\title{
EXPERIENCIAS DE ANIMACIÓN SOCIOCULTURAL Y VOLUNTARIADO IMPULSADAS POR EL PROGRAMA ACADÉMICO DE GESTIÓN CULTURAL EN LA UNIVERSIDAD DE PIURA-PERÚ
}

Diana Aguirre Manrique ${ }^{(*)}$

\section{ANTECEDENTES Y CONTEXTO}

Desde el 2003, la Universidad de Piura ofrece la licenciatura de Historia y Gestión Cultural, en la Facultad de Humanidades; desde el cual, la Universidad impulsa la investigación y el diseño de proyectos en los diferentes ámbitos de la cultura. Con este fin, los docentes nos especializamos en algunos campos concretos; en mi caso, en patrimonio inmaterial, con el propósito de dar énfasis a la investigación y difusión del mismo. En los diversos proyectos impulsados desde la Facultad, se ha promovido la participación de los alumnos y exalumnos de la licenciatura, lo que los ha enriquecido a todos en la práctica de la gestión cultural.

Este marco es importante para entender que, a partir de la investigación de la artesanía de sombreros de paja toquilla en el distrito de Catacaos desarrollada desde el 2006, hemos podido conocer el entorno socio económico y cultural de los pobladores asociados a esta práctica artesanal y consolidar acciones para su salvaguardia. Por ejemplo, en el 2013 se publicó la investigación en el libro El sombrero de Catacaos. Tejiendo su historia, la declaratoria de este sombrero como Patrimonio de la Nación. Este contexto fue el punto de partida del Proyecto alma Tallán, nacido para incentivar el interés de los jóvenes y niños de las comunidades de tejedores en su patrimonio local y en su salvaguardia.

lma Tallán, desarrollado por voluntarios universitarios, toma como base la aplicación de la animación socio cultural para hacer que los miembros de la Comunidad de la Campiña Catacaos sean los principales agentes dinamizadores de la cultura. A través de diversos talleres educativos, artísticos y culturales, busca fortalecer la identidad local y el desarrollo de habilidades en niños, jóvenes y mujeres artesanas. Del 2013 a la fecha, va consolidando un modelo de proyecto que conecta el trabajo solidario, a través del voluntariado, con la Defensa del Patrimonio Cultural, poniendo especial énfasis en la difusión y la participación activa de la comunidad.

\footnotetext{
${ }^{(*)}$ Máster en Gestión del Patrimonio Cultural y Natural. Professora da Universidad de Piura, Peru. E-mail: diana.aguirre@udep.pe.
} 


\section{Breve descripción contextual}

Catacaos está ubicado a $12 \mathrm{~km}$, al sur este de la ciudad de Piura, en el norte del Perú. Sus poblados están rodeados por un valle productor de arroz, cebolla, maíz, algodón, etc.; es por eso que la mayoría se dedica a las faenas agrícolas - ganaderas. Sin embargo, tienen aún serios problemas de saneamiento básico, calidad educativa y servicios de atención primaria de salud, reflejados en un IDH bajo $(0,56)$.

Pese a ello, el distrito de Catacaos es reconocido como la Capital artesanal y turística de la región, porque allí se se desarrolló uno de los centros administrativos - religiosos de la Cultura Tallán, cuya herencia ha quedado impregnada en los restos arqueológicos de la zona, en la destreza artesanal que caracterizó a los tallanes, en el carácter luchador de las mujeres (llamadas capullanas), etc. Además, alberga varias expresiones culturales, fruto del mestizaje cultural, que se han arraigado en este territorio, como: la filigrana de plata (técnica de tejido en hilos de plata y oro ), la Semana Santa, los carnavales y, de manera especial, la sombrerería en paja toquilla. Todo esto hace que sea uno de los lugares más visitados de Piura.

En Catacaos encontramos uno de los conglomerados sombrereros más singulares del norte del Perú, surgido en el siglo XVIII. Está conformado por las tejedoras de los poblados de Narihualá, Pedregal Grande, Pedregal Chico y La Campiña, todos ellos ubicados en los alrededores de la huaca de Narihualá.

Los sombreros cataquenses tuvieron fama mundial, hecho que está plenamente documentado y que sitúa a este distrito en el boom sombrerero que se dio en el mundo, desde finales del siglo del siglo XIX hasta mediados del siglo XX. Los famosos Panamá Hat fueron producidos también por manos cataquenses junto a las de otros tejedores de Ecuador y Colombia. Hemos encontrado referencia de sombreros tan finos que se podían guardar en el bolsillo como un pañuelo.

En esas épocas tejían todos los miembros de la familia, en especial los hombres; pero, en la actualidad es un oficio que solo practican las mujeres.Las artesanas jóvenes desconocen la técnica de tejido de sombrero, en especial del tejido fino y el valor de este tejido como Patrimonio de la Nación; además,tienen poco interés por seguir manteniendo esa tradición, que requiere de un minucioso trabajo de baja compesación económica, pese a que existen seis asociaciones consolidadas de artesanas.

Las ayudas de capacitación recibidas e implemantación de talleres en los últomos 30 años han sido importantes pero no han conseguido potenciar el mercado sombrerero y la transmisión de la técnica a los más jóvenes. Se ha dado más impulso a otros pruductos de paja más comerciales y 
de menor tiempo de trabajo. Por otro lado, se ha comprobado el desconocimiento que existe del valor histórico y cultural de esta tradición sombrerera y el escaso reconocimiento de esta artesanía como patrimonio.

Los hijos e hijas de tejedoras de sombreros de paja toquilla se encuentran en una situación de exclusión social, por las escasas oportunidades de acceder a una educación de calidad y al desarrollo de sus habilidades personales. Por estas razones, se requiere de programas de Educación no formal que les brinde oportunidades para complementar su formación.

\section{La Campiña - Narihualá}

De los poblados rurales que forman parte del conglomerado donde se teje el sombrero cataquense, hemos escogido a la Comunidad La Campiña- Narihualá el centro de operaciones de este proyecto. Está conformada por 2300 habitante; alrededor de 320 son mujeres y, de estas, unas 200 son artesanas tejedoras. Es decir, la mayoría de las familias se sostienen o complementan su economía gracias a la venta de los productos de paja: porta botellas, cestas y sombreros principalmente.

Entre los motivos por los cuales escogimos esta comunidad descatan las siguientes:

a) La existencia de una Asociación de tejedoras denominada “ Virgen del Pilar”, dirigida por una artesana distinguida con el premio Amauta de la Artesanía peruana, con visión de trabajo en equipo y dispobilidad para liderar el proceso.

b) Las integrantes de la Asociación tienen entre 22-35 años.

c) Hay un local comunal con espacios adecuados para la realización de los talleres.

d) Por su cercanía a la Huaca de Narihualá, lo que posibilita el trabajo integral de patrimonio local material e inmaterial, cultural y natural.

\section{PROYECTO ALMA TALLÁN: ANIMACIÓN SOCIOCULTURAL Y VOLUNTARIADO}

Para describir de manera ordenada las experiencias de animación sociocultural y voluntariado en el proyecto Alma Tallán, hemos organizado el texto siguiento las tres etapas cronológicas de su desarrollo: Diseño e implentación (2013- 2014), Proyecto piloto de reforzamiento (2015) y Rediseño( 2016). 


\section{Diseño e implementación ( 2013- 2014)}

El proyecto Alma Tallán: Recuperación de tradiciones culturales y formador de formadores en los centros poblados aledaños al Sitio arquoelógico de Narihualá Catacaos- Piura- Perú fue elaborado para participar en la convocatoria anual de Proyectos Culturales del BID, esultando ganador para ser financiado. Se ejecutó de julio a diciembre de 2013, teniendo como institución gestora a la Universidad de Piura (UDEP); y a otras entidades locales, como socias estratégicas. El equipo de trabajo estuvo conformado por 8 universitarios voluntarios y 4 profesionales de la cultura.

Como fin, este proyecto se planteó reactivar la recuperación de tradiciones artesanales y culturales en los centros poblados aledaños a la huaca Narihualá (Catacaos), que permita fomentar la creatividad y el emprendimiento en jóvenes, para contribuir así a la mejora de la calidad de vida de las familias artesanas. Para ello, se definió el siguiente objetivo general: Diseñar e implementar un programa de capacitación dirigido a tejedoras; y la formación a formadores en animación sociocultural, para la recuperación de la técnica de tejido fino de paja toquilla. Para lograrlo, se diseñaron dos programas de fortalecimiento de capacidades: uno dirigido a las artesanas mayores para perfeccionar su técnica; y el otro, a las/los jóvenes tejedoras para formarlas como animadores socioculturales, con la clara misión de motivar el interés de otros jóvenes y niños de la comunidad, por la recuperación de sus tradiciones.

A continuación, describiremos brevemente las dos fases de trabajo realizadas:.

\section{FASE I: Fortalecimiento de capacidades "Formador de formadores"}

La transmisión de la técnica a los más jóvenes de la zona que no practican este arte, es una tarea imprescindible para la salvaguarda de esta artesanía. Y más aún si la mayoría de jóvenes que terminan la escuela secundaria no pueden continuar estudios superiores. A través de la recuperación de tradiciones y el desarrollo de habilidades, los jóvenes pueden generar pequeños emprendimientos que les permita forjarse un mejor futuro y minimizar del riesgo de exclusión social. Por eso, se planteó el programa de "Formador de formadores", a cargo de los voluntarios culturales de la Universidad de Piura, a través de su programa de Voluntariado Cultural. Alumnos y exalumnos de la licenciatura de Historia y Gestión Cultural se orientaron básicamente a desarrollar en los jóvenes los conocimientos, habilidades y actitudes que les permita contribuir a la reactivación de la práctica artesanal y logren motivar a los niños y jóvenes de la comunidad para que participen en este proceso. Esta formación es un pilar fundamental en el proyecto, porque para realizar con éxito este proceso se necesita fortalecer capacidades claves para la animación sociocultural. 
Esta capacitación comprende tanto el manejo de técnicas instrumentales como el manejo de ciertas claves para la comprensión de la realidad. Se trata de formar y potenciar a líderes naturales, a los animadores voluntarios y a la gente en general. (Egg: 2002, p. 105)

Se organizó un grupo base de 6 jóvenes tejedores quienes recibieron los primeros talleres de empoderamiento del proyecto. De este modo se convirtieron en los principales portavoces para convocar a otros jóvenes, de entre 17 a 22 años, con interés en aprender tejido de paja y participar en el programa de formación como animadores socioculturales.

Cerca de 30 jóvenes iniciaron el programa y se logró consolidar un equipo de 20 animadores. La formación abordó 4 temas fundamentales: la historia y patrimonio local, técnicas de animación sociocultural, estrategias de trabajo con niños y talleres de tejido. Los estudiantes, voluntarios de la UDEP, prepararon módulos de formación para facilitar la trasmisión de conocimientos. Después de dos meses de preparación, los jóvenes estuvieron listos para desarrollar su labor de manera voluntaria en dos colegios y en la escuela Alma Tallán, espacio implementado en el local comunal para desarrollar talleres artísticos y artesanales con niños de entre 8 a 12 años.

Como complemento fundamental para la motivación de jóvenes animadores se iniciaron alianzas estratégicas, para consolidar pequeños emprendimientos que les asegure una retribución económica, y desarrollaron su labor como animadores socioculturales voluntarios. Para lograrlo, se promocionó un producto educativo- cultural dirigido a escolares de la ciudad, para que visiten la huaca de Narihualá y realicen un taller de tejido en la Campiña. Esta y otras iniciativas contribuyeron a la continuidad del trabajo de los jóvenes en la escuela Alma Tallán durante el 2014.

\section{FASE II: Desarrollo del programa de animación sociocultural}

Antes de explicar en qué consistió esta fase, es importante precisar las bases conceptuales que fundamentan este trabajo. Entendemos animación sociocultural como:

un método de intervención, con acciones de práctica social, dirigida o destinada a animar, ayudar, dar vida, poner en relación a los individuos y a la sociedad en general, con una adecuada tecnología y mediante la utilización de instrumentos que potencien el esfuerzo y la participación social y cultural..(MERINO: 1997, p.39).

Si bien no hay un consenso para establecer una única definición, consideramos que esta contiene los elementos esenciales para nuestro estudio, porque se buscó principalmente dar vida o motivar la recuperación de las tradiciones locales, para que impulsen la mejora de las perspectivas de vida de la comunidad.

Entendimos rápidamente que este programa tendría que dirigirse al ámbito educativo tanto en su dimensión formal y no formal. En el caso de este último, fundamentamos nuestro trabajo en la 
Educación patrimonial porque buscamos el desarrollo de conocimientos, habilidades y actitudes que faciliten la formación integral de los niños, tomando como eje la revalorización del patrimonio local. Es decir, el patrimonio como recurso para el aprendizaje. Esta disciplina emergente busca además:

...la promoción de valores cívicos, éticos y afectivos en relación con la defensa y protección de los elementos patrimoniales... que ayuden a la construcción de la identidad de los sujetos. (CALAF: 2006, p.53)

Guiados por estos planteamientos teóricos y la formación técnica en la escuela Alma Tallán, los días domingos, los niños participaron de diversos talleres de artes plásticas y artesanía, a través de los cuales descubrieron el valor de su historia y el patrimonio.

En la preparación del programa y la formación de jóvenes animadores y profesores colaboraron bachilleres en Gestión Cultural, quedando definido que la animación sociocultural se realizaría en dos ámbitos de actuación: dos colegios primarios y la escuela Alma Tallán en Narihualá- La Campiña. En este programa se beneficiaron 5 profesores, 6 jóvenes, 120 niños de $4^{\text {to }}$ y $5^{\text {to }}$ de Primaria y alrededor de 250 niños en la escuela Alma Tallán; el periodo de ejecución duró tres meses. A continuación presentamos el contenido del programa en los dos ámbitos mencionados:

Tabla 1. Talleres en el ámbito educativo formal y no formal

\begin{tabular}{|c|c|c|c|}
\hline Programas & Talleres & Lugar & Edades \\
\hline \multirow{3}{*}{$\begin{array}{l}\text { Educación no formal } \\
\text { (Los días domingos en la } \\
\text { escuela Alma Tallán) }\end{array}$} & Aprendiendo a tejer: técnica del tejido fino & \multirow{3}{*}{$\begin{array}{l}\text { Escuela Alma } \\
\text { Tallán } \\
\text { (Local } \\
\text { Comunal) }\end{array}$} & \multirow{3}{*}{8 a 12 años } \\
\hline & $\begin{array}{l}\text { Dibujo y pinto mi tradición: Descubriendo mis } \\
\text { raíces culturales: Narihualá-Tallán }\end{array}$ & & \\
\hline & $\begin{array}{l}\text { Difundiendo mi cultura: pequeños arqueólogos y } \\
\text { guías locales }\end{array}$ & & \\
\hline $\begin{array}{l}\text { Educación formal } \\
\text { (Durante el horario de clases } \\
\text { y ligado a la programación } \\
\text { curricular) }\end{array}$ & $\begin{array}{l}\text { El "sombrero didáctico" } \\
\text { Cinco sesiones teórico- prácticas de los siguientes } \\
\text { temas: } \\
\text { Catacaos, su entorno y su cultura. } \\
\text { Los Tallanes y la huaca de Narihualá. } \\
\text { El sombrero de paja Toquilla. } \\
\text { Josefina Ramos de Cox y su legado. } \\
\text { Tradiciones, costumbres y leyendas. } \\
\text { Dos sesiones prácticas: } \\
\text { "Aprendiendo a tejer la técnica del tejido fino" }\end{array}$ & $\begin{array}{l}2 \text { Centros } \\
\text { educativos de } \\
\text { nivel Primaria } \\
\text { de la zona. } \\
4^{\text {to }} \text { y } 5^{\text {to }} \text { de } \\
\text { Primaria }\end{array}$ & 9 a 11 años \\
\hline
\end{tabular}

En la escuela Alma Tallán los colores, plumones, témperas, plastilina y la paja son la base de los talleres que buscan descubrir a los niños el valor de sus tradiciones culturales. Se divierten mientras aprenden $\mathrm{y}$, luego, participan orgullosos en los concursos de tejido de pequeños 
sombreros. Además, realizan una visita a la huaca de Narihualá donde los animadores profundizan sus conocimienrtos históricos.

\section{El "sombrero didáctico": Una experiencia de educación patrimonial}

Fue la estrategia utilizada para descubrir en los alumnos el valor del sombrero de paja toquilla, a la que denominamos "sombrero didáctico" que, como ya hemos señalado, intenta aplicar los principios de la educación patrimonial.

El "sombrero didáctico" se inspira en la estrategia metodológica utilizada comúnmente en el museo, llamada la maleta didáctica, que contiene objetos, imágenes, videos y fichas de trabajos que incentivan la participación interactiva de entre el público y el animador sociocultural. Esta actividad resulta motivadora para los públicos visitantes, principalmente los niños. En nuestro caso se trata por tanto de un kit educativo que contiene objetos, fichas y actividades que desarrollan diversos contenidos curriculares relacionados con el sombrero de paja y la historia del poblado. Hemos querido que este recurso se inspire en el bien patrimonial que pretendemos revalorar; es decir, un sombrero de paja hecho en junco, la primera fibra utilizada por los pobladores para tejer los sombreros.

Para el planteamiento de esta estrategia se hizo un trabajo conjunto entre gestores culturales y profesores para ligar los temas a la programación curricular y la elaboración de las fichas de trabajo con actividades interdisciplinares. Por otro lado, hicimos objetos en miniaturas, imágenes, videos y mapas, relacionados con la historia, patrimonio y tradiciones, que se colocarán dentro del sombrero. Estos materiales serán los medios que servirán de motivación para desarrollar los temas en las sesiones de aprendizaje.

\section{El "sombrero didáctico" consta de lo siguiente:}

- Un sombrero de junco de $40 \mathrm{~cm}$ de diámetro y $30 \mathrm{~cm}$ de alto. Es un cofre donde la copa es la tapa y la falda es el interior del cofre.

- Un maíz en miniatura. Técnica usada: cerámica en frío.

- Una arqueóloga en miniatura. Técnica usada: cerámica en frío.

- Un perro viringo en miniatura. Técnica usada: cerámica en frío.

- Un manojo de paja toquilla.

- Un libro "El sombrero de paja de Catacaos: tejiendo su historia".

- Un CD/DVD con videos acerca de Catacaos, Narihualá, el perro viringo, el sombrero de paja de Catacaos y la chicha de jora.

- Doce bits de inteligencia con las siguientes imágenes: perro viringo, bajada de reyes, Josefina Ramos de Cox, artesana tejiendo, sombrero de paja de Catacaos, lagarto de 
oro, Narihualá-zona arqueológica, museo de sitio de Narihualá, chicha de jora, instrumentos para tejer el sombrero, capullana y el valle de Catacaos.

- Veinticinco folletos informativos IPerú que incluyen mapas de Piura región.

- Cinco fichas didácticas con actividades y ejercicios de afianzamiento de lo aprendido.

El “sombrero didáctico”, a través de las cinco sesiones temáticas y dos sesiones prácticas, intentará despertar en los niños el interés por su patrimonio y su compromiso en la difusión. Los jóvenes animadores socioculturales se encargaron de apoyar a los maestros en las sesiones de aprendizaje, a las que hemos denominado "Descubriendo mis raíces", estas se dearrollaron en torno a los siguientes temas:

1. Catacaos, su entorno y su cultura: Taller en el que reforzarán sus conocimientos acerca de la geografía de su zona, actividades económicas y su cultura en general. Es una sesión introductoria

2. Los Tallanes y la huaca de Narihualá: Se les impartirá conocimientos históricos acerca de los Tallanes y de la huaca de Narihualá. Además, se les capacitará en la importancia de su conocimiento y conservación.

3. El sombrero de paja toquilla como patrimonio de la Nación: taller en el que se capacitará sobre la historia sombrero de paja de Catacaos y la importancia de la técnica del tejido fino de paja toquilla.

4. Josefina Ramos de Cox y su legado: Conocerán y aprenderán de Josefina Ramos de Cox, arqueóloga cataquense reconocida por sus investigaciones acerca de la historia prehispánica de Piura como son los tallanes y la arqueología como lo es la huaca de Narihualá.

5. Tradiciones, costumbres y leyendas de Narihualá: Este taller reforzará el conocimiento de las tradiciones, costumbres y leyendas de Narihualá como es la preparación de la chicha de jora, la festividad de la bajada de reyes, la leyenda del lagarto de oro, entre otras.

La evaluación se dirige tanto a los profesores como a los alumnos. A los maestros se les hizo entrega de una ficha de evaluación con preguntas referentes al aprendizaje de los temas por parte de los alumnos, su desempeño y motivación. A los niños se les entregó una ficha final de evaluación que resumirá en actividades los distintos temas aprendidos en las diferentes sesiones.

Las dos sesiones prácticas tienen como título "Aprendiendo a tejer la técnica del tejido fino”. Una maestra artesana y dos de los jóvenes animadores socioculturales con experiencia en tejido eneseñan a los niños a tejer un sombrero pequeño. El resultado de este trabajo se expuso en el 
día del logro, espacio creado por el Ministerio de Educación para mostrar los avances de los niños en ciertos aprendizajes.

\section{RESULTADOS}

Los jóvenes animadores socioculturales lograron consolidar un equipo que siguió atendiendo la escuela Alma Tallán durante el 2014. Se recibió la ayuda de la ONG Punto de Apoyo ${ }^{1}$ para darle continuidan a la formación en empendimiento y la difusión de sus productos a través de campañas especiales de venta que esta ONG realiza en la ciudad de Lima.

La Asociación "Virgen del Pilar" fortaleció sus contactos con instituciones nacionales, como la Dirección de Artesanías del Ministerio de Cultura, logrando participar en la Feria Nacional Ruraq Maqui, invitación que han mantenido en estos años. Con el Museo de Arte de Lima (MALI) lograron participar en la Subasta anual subasta anual de artesanías, logrando vender 3 sombreros de tejido fino a un buen precio.

En los dos centros educativos se dejó KIT del Sombrero Didactico. Además, en uno de ellos se incluyó el dictado de clases de tejido una vez por semana. Este taller lo tuvo a cargo la artesana Juana Solano, distinguida el 2014 como Amauta de la artesanía peruana, justamente por su dedicación a la transmisión de la técnica del tejido en su comunidad.

Los voluntarios Culturales de la UDEP recibieron por esta labor la acreditación como Defensores del Patrimonio del Ministerio de Cultura del Perú.

La visibilización del proyecto en la prensa local y su reconocimiento han motivado a los integrantes del proyecto a continuar la labor y aplicar las estrategias más adecuadas para su sostenibilidad

\section{PROYECTO PILOTO DE REFORZAMIENTO (2015)}

El 2014 el voluntariado Brigadas Culturales al que pertenecía el proyecto Alma Tallán deja de funcionar. Por ese motivo solo se mantuvo el monitoreo a los jóvenes por parte de los profesores impulsores del proyecto y la organización del festival Alma Tallán.

Sin embargo, en el 2015 el panorama del voluntariado en la Universidad tuvo un giro importarse al crearse un área coordinadora de estas iniciativas solidarias. Esto dio la oportunidad para que el equipo de profesores impulsores propusieran la continuidad del proyecto Alma Tallán e

\footnotetext{
${ }^{1}$ ONG formada por profesionales de administración y psicología en la ciudad de Lima el 2014.
} 
intruducir algunos cambios para su mejora. Uno de estos cambios fue la inclusión de voluntarios de todas las facultades en este proyecto. De esta manera los conocimientos que los universitarios van adquiriendo durante su formación académica las pondrán al servicio de la mejora integral de la Comunidad a través de los talleres.

Así surgió el proyecto piloto Alma Tallán. Programa de fortalecimiento de la identidad, emprendimiento cultural y habilidades sociales para contribuir al desarrollo personal de los jóvenes y niños de La Campiña-Narihualá. Siempre bajo el modelo formador de formadores y aplicando la animación sociocultural se inició esta nueva experiencia enriquecida por la interdisciplinariedad. El equipo de trabajo estuvo conformado por 20 universitarios de las facultades de Derecho, Comunicación, Humanidades y Empresas. Además de 5 profesionales entre docentes y ex alumnos de la Universidad. Es importante recalcar que en esta etapa no se contó con financiamiento externo, por lo que gastos fueron financiados por los voluntarios y amigos. Esto ha fortalecido el compromiso solidario tanto en los universitarios como en la comunidad.

A diferencia del Proyecto inicial este piloto se focalizó en el ámbito no formal y por tanto trabajó solo con jóvenes y niños en la Escuela Alma Tallán. Y si bien ya no se contó con los fondos del BID, se planteó un financiamiento basado en el aporte voluntario de los participantes tanto de la Universidad como de la Comunidad. Además de algunas instituciones y amigos de los implicados.

El lanzamiento del programa se realizó en agosto de 2015, en el marco del aniversario de la Comunidad. Para ello se organizó de manera conjunta el "Primer Concurso de tejido de sombreros para niños: Tejiendo el futuro". De esta manera buscamos incentivar la valoración y uso de esta artesanía por parte de los más pequeños, motivando a las madres artesanas a tejer un sombrero para sus hijos o nietos. En este aniversario tuvimos la presentación de la Orquesta Sinfónica Municipal quienes gracias a las gestiones conjuntas Universidad- Comunidad pudieron deleitar a los pobladores con un concierto didáctico.

En la primera fase los jóvenes de la Comunidad recibieron formación en tres ámbitos específicos (Ver Tabla 2), interactúan con los universitarios y coordinan con ellos trabajo a realizar con los niños en la segunda fase. Este Plan formativo se realizó tomando como base los intereses de los jóvenes para asegurar la motivación y perseverancia en el proyecto. 
Tabla 2. Programa de formación de los Jóvenes de la Comunidad

\begin{tabular}{|c|c|}
\hline Ámbitos de acción & Descripción \\
\hline Patrimonio Cultural (PC) & \multirow[b]{2}{*}{$\begin{array}{l}\text { Consistirá en realizar sesiones teórico- prácticas } \\
\text { para que los jóvenes conozcan más su } \\
\text { patrimonio. Se dará énfasis al conocimiento del } \\
\text { sitio arqueológico y la lucha contra el tráfico } \\
\text { ilícito de bienes culturales }\end{array}$} \\
\hline $\begin{array}{l}\text { 1. Descubriendo nuestro patrimonio. Visita a la Huaca de } \\
\text { Narihualá. } \\
\text { 2. El huaqueo y el tráfico ilícito. } \\
\text { 3. ¿Cómo llenar una ficha de identificación de un bien cultural? } \\
\text { 4. Difundo lo aprendido: visita de familias para sensibilizarlos } \\
\text { sobre el tema. } \\
\text { Producto: Exposición gráfica de lo aprendido. }\end{array}$ & \\
\hline Emprendimiento Cultural (EC) & \multirow[b]{2}{*}{$\begin{array}{l}\text { Consistirá en asesorar a los jóvenes tejedores en } \\
\text { los productos que presentarán en la feria Ruraq } \\
\text { Maki en el mes de diciembre (Lima) y el } \\
\text { concurso de nacimientos en Catacaos. }\end{array}$} \\
\hline $\begin{array}{l}\text { 1. La planificación: organización del grupo y cronograma y } \\
\text { presupuestos. } \\
\text { 2. Definición de productos. Asesoría en diseño y calidad. } \\
\text { 3. Definición de la marca de los productos. Sesión de fotos. } \\
\text { 4. Definición de empaques de presentación, difusión por la web y } \\
\text { precios de productos. } \\
\text { Producto: Presentación en una feria y el concurso. }\end{array}$ & \\
\hline Habilidades Sociales (HS) & \multirow{2}{*}{$\begin{array}{l}\text { Consistirá en desarrollar una habilidad artística } \\
\text { que les permita desarrollar una serie de } \\
\text { actitudes que posibiliten el trabajo en equipo, la } \\
\text { integración y la creatividad. Para ello se ha } \\
\text { elegido la música y el canto coral. }\end{array}$} \\
\hline $\begin{array}{l}\text { Sesiones prácticas de apreciación musical y ejercicios vocales. } \\
\text { Ensayo de los cantos. } \\
\text { Producto: Presentación artística en Navidad. }\end{array}$ & \\
\hline
\end{tabular}

Los talleres ofrecidos para los niños siguieron el formato del proyecto inicial y fueron “Aprendiendo a Tejer” y "Dibujo y Pinto mi tradición”.

La clausura del programa se realizó con el Festival Alma Tallán en el que los niños participantes de los talleres ponen a prueba sus talentos artísticos en diversos concursos. Además se realizó otro concurso para implicar a las artesanas mayores y sus hijos, esta vez para tejer una rosa de manera conjunta.

\section{RESULTADOS}

Este proyecto piloto nos permitió retomar el contacto con los pobladores y conocer más sus intereses. De este modo se pudo relanzar el proyecto cada vez con más participación de las autoridades y la Comunidad. Constatamos que el nombre Alma Tallán se va posicionando en el imaginario de los pobladores. 
Los talleres de los jóvenes captaron interés de 15 jóvenes (17 - 24 años) pero tuvieron más presencia de mujeres que de varones. Lo que planteó el reto de buscar propuestas más atractivas.

En los talleres de niños se logró la participación de 120 y alrededor de 200 en el festival Alma Tallán, que además incluyó una chocolatada navideña.

Las artesanas mayores, miembros de la asociación, se sintieron contentas e integradas al proyecto por la participación en los concursos. Además, se logró la presencia de las autoridades y otros pobladores no asociados al tejido en las actividades organizadas.

Los voluntarios universitarios renovaron la certificación nacional como Defensores del Patrimonio y pudieron usar por primera vez el chaleco y gorra como distintivo en sus labores.

La visibilización del proyecto a nivel local empieza a consolidarse principalmente por la difusión en los medios de prensa local y redes sociales, por lo que el apoyo institucional se va fortaleciendo y animando a los organizadores a seguir mejorando la propuesta.

\section{6: RE DISEÑO Y EXPERIENCIA DE LA PRIMERA FASE}

Enriquecidos por la experiencia de estos años de trabajo con la comunidad y con más interés de jóvenes universitarios por hacer voluntariado en este proyecto, nos propusimos darle el formato definitivo para consolidarlo y complementarlo incluyendo esta vez una nueva propuesta de gestión de recursos económicos que nos permitan lograr con mayor eficacia en el fortalecimiento de capacidades en las familias de tejedores de la Campiña- Narihualá para el 2017.

Alma Tallán en honor a su denominación "alma" busca animar a la comunidad a la consecusión de su desarrollo fortaleciendo la participación, el diálogo intercultural, la inclusión social, el emprendimiento y la cohesión. Por eso, toma como herramienta la animación sociocultural y se basa en la fuerza solidaria y creativa de los jòvenes universitarios. Estos elementos le dan un alto potencial para mediar exitosamente en este proceso de revitalización cultural en esta comunidad. Como bien precisa Lozano (2014) resumiendo algunas ideas de Gabriel Restrepo sobre la labor del gestor cultural:

....alguien que genera lazos y conecta personas, haciendo tramas entre ellas. El placer de crear estas tramas sociales es también el placer de facilitar experiencia de aprendizaje con ello. (p. 100).

Con bases más sólidas renació Alma Tallán como un Proyecto de fortalecimiento de la identidad local, emprendimiento cultural y habilidades sociales dirigidas a familias de tejedoras de La Campiña- Narihualá- Catacaos teniendo como objetivo principal desarrollar capacidades para 
mejorar la identidad, el emprendimiento y las habilidades sociales en las familias de tejedoras del centro poblado La Campiña, Narihualá. El equipo de trabajo de este año está conformado por 30 universitarios de las Facultades de Derecho, Educación, Comunicación, Humanidades y Empresas. Además de 6 profesionales entre docentes y ex alumnos de la Universidad.

El proyecto Alma Tallán se dirige a las familias de la comunidad, empezando por las 40 que forman parte de la asociación, por eso propone actividades para mujeres tejedores, jóvenes y niños, que serían el público beneficiario directo. Sin embargo, contempla actividades de impacto en toda la Comunidad. El programa de actividades se ha formulado en base a las habilidades de los voluntarios universitarios y los intereses de la Comunidad.

Tiene como siempre en dos fases de trabajo, la primera es impresciendible para el trabajo conjunto entre los voluntarios universitarios y los jòvenes de la comunidad, tanto para el desarrollo de habilidades como para la co planificación de las actividades porque el trabajo que se realiza con los universitarios es en base al criterio de entre iguales donde todos aportan y aprenden. Buscamos además que estos jóvenes asuman el liderazgo en su comunidad y sean los que convoquen, motiven y organicen a la población para su participación.

En la primera fase los talleres "Alma Fotera", "La Voz de la Campiña" y "Emprende Tallán” buscarán desarrollar diversas habilidades en los jóvenes e involucrarlos con los objetivos del proyecto y se sientan co partícipes de éste. La meta de este año es llegar a 25 jóvenes. En la segunda fase se realizarán las actividades dirigidos a niños y mujeres artesanas. ( Ver Tabla 3)

Tabla 3. Programa general de actividades de formación del proyecto Alma Tallán 2016

\begin{tabular}{|c|c|c|c|}
\hline PROGRAMA & Público objetivo & Actividad & FASES \\
\hline \multirow[t]{2}{*}{$\begin{array}{l}\text { Emprendimiento } \\
\text { Cultural }\end{array}$} & Mujeres artesanas & Capacitaciones sobre Calidad e innovación. & $\mathrm{F} 2$ \\
\hline & Jóvenes & $\begin{array}{l}\text { Taller "Emprende Tallán". Diseño de una ruta } \\
\text { cultural educativa. }\end{array}$ & $\mathrm{F} 1$ \\
\hline \multirow[t]{2}{*}{ Identidad local } & Jóvenes & Taller de Fotografías: "Alma Fotera" & $\mathrm{F} 1$ \\
\hline & Niños & $\begin{array}{l}\text { Taller "Dibujo y Pinto mi tradición". } \\
\text { Taller "Aprendiendo a Tejer". }\end{array}$ & $\mathrm{F} 2$ \\
\hline \multirow[t]{3}{*}{ Habilidades sociales } & Mujeres & Taller de manualidad y tejido & F2 \\
\hline & Jóvenes & Taller de radio " La voz de la Campiña" & F1 \\
\hline & Niños & $\begin{array}{l}\text { Taller de radio " La voz de la Campiña” } \\
\text { Taller de Música y canto }\end{array}$ & F2 \\
\hline
\end{tabular}


Otro aspecto imporante es el involucramiento de las familias de tejedores y las autoridades locales, para lo cual tenemos un plan de visitas con actividades para desarrollar con ellas. De manera paralela a los talleres, se realiza la actividad denominada Visita a las familias Tallán que permite a los voluntarios socializar con las artesanas para conocer mejor sus intereses y necesidades. Además permite mantener comunicación directa con las familias sobre las actividades en las que participan sus hijos y motivar su asistencia puntual y responsable.

En cuanto a la gestión económica del proyecto, se han establecido algunas estartegias para la obtención de recursos que permitan que en el 2017 este proyecto pueda ser existoso también en la generación de recursos propios y conseguir financiamiento de entidades de prestigio en la Región. Un primer paso para lograrlo ha sido fortalecer el plan de comunicación en redes sociales y diaros locales, justamente por la presencia de alumnos de la Facultad de Comunicación de la Universidad y el apoyo de la Dirección de Comunicación de la Universidad.

En un futuro inmediato pensamos gestionar convenios con instituciones educativas de nivel Técnico-Superior que permita a los jóvenes de la comunidad estudiar y obtener un título profesional que les asegure una fuente de trabajo. Todo esto sin dejar de lado el impulso de su habilidad artesanal complementándola con otros conocimientos empresariales, diseño, de comunicación y márketing que les permita darle a su artesanía un valor agregado.

\section{EXPERIENCIA DE LA FASE I DEL 2016}

Al cierre de este artículo se ha concluido con la primera fase del proyecto con gran satisfacción. Se inscribieron 24 jóvenes en los talleres y de ellos se ha conformado un grupo de 15 animadores que tendrán a cargo la segunda fase del proceso y actualmente organizan el aniversario de la comunidad junto con sus autoridades. Tendremos en breve el "II Concurso de Tejido de Sombrero para niños : Tejiendo el futuro".

Las actividades desarrolladas por el Taller de Radio "La Voz de la Campiña” fueron las más representativas de estafase, porque los jóvenes lograron grabar su primer programa en el Centro de Producción audiovisual de la Universidad (CPA) para transmitirlo por las emisoras de la localidad. Los jóvenes aprendieron a preparar entrevistas y radio teatro, para lograrlo tuvieron que investigar sobre su patrimonio local y aplicar algunas estrategias de locución y dicción. El resultado se esta expriencia ha sido difundida en la prensa local y ha logrado entusiasmar a los participantes por 
seguir perteneciendo a este proyecto de voluntariado. ${ }^{2}$ En las próximas semanas se espera mostrar los resultados de los otros talleres e iniciar la segunda fase.

\section{A MANERA DE CONCLUSIÓN}

Animación Sociocultural como herramienta de la Gestión Cultural permite una acción transformadora de la Comunidad. En este proyecto intentamos aplicar algunas de sus directrices metodológicas que según Manuel Collado y Víctor Alvares (QUINTANA: 1992) se deben notar en todo el proceso de planificación y en el cómo se realiza este proceso, al que le llaman talante metodológico. En nuestra experiencia vamos aplicando estas orientaciones en lo siguiente:

- Conocimiento del medio basado en una experiencia cercana y progresiva,

- Apertura al diálogo con los líderes de la comunidad y acercamiento continuo a ellos.

- Determinación de necesidades y expectativas

- Respetar la autonomía y la participación voluntaria de la comunidad.

- Fomentar la participación activa y el compromiso personal.

- Retroalimentar constantemente las iniciativas y contrastarla con los involucrados.

- Formar gestores o animadores con actitud de diálogo y atentos a las necesidades que van surgiendo.

Este proyecto se propuso contribuir a la salvaguardia del Sombrero de Paja Toquilla como Patrimonio pero basándose en el fortalecimiento de la participación activa de la comunidad. Se trata de un proceso lento pero gratificante que sin duda verá en el futuro concretar el gran objetivo tener una comunidad identificada con su cultura, emprendedora y creativa, con herramientas para encaminarse hacia un desarrollo sostenible.

\section{REFERÊNCIAS}

EGG, A. La Práctica de la Animación Sociocultural y el Léxico del Animador. Lima, Perú: Fondo Ed. Pontificia Universidad Católica del Perú. 2002.

CALAF, R. ; FONTAL, O. (Coords.). Miradas al patrimonio. Gijón : Ediciones Trea. 2006.

LOZANO, J. La vieja Nueva Gestión Cultural y sus vínculos con la animación socio cultural y la educación. In: YAÑEZ, C. (Coord.). Emergencias de la Gestión Cultural en América Latina. Bogotá. Universidad Nacional de Colombia, 2014. P. 84-109.

MERINO, J. Programas de animación sociocultural: tres instrumentos para su diseño y evaluación. Madrid. 1997.

QUINTANA, J. M. (Coord.). Fundamentos de la Animación Sociocultural. Madrid: Narcea, S.A. 1992.

\footnotetext{
${ }^{2}$ Para ampliar información ver el link: http://udep.edu.pe/hoy/2016/voluntarios-fortalecen-identidad-y-emprendimiento$\underline{\text { en-la-campina/ }}$
} 


\section{RESUMEN}

Las experiencias descritas se centran, de manera especial, en el Proyecto "Alma Tallán", surgido el 2013. En él se aplica la animación sociocultural, como herramienta para fomentar la participación comunitaria en la salvaguardia del patrimonio local. La participación de la población, en las actividades culturales y educativas propuestas, consolida al patrimonio como un recurso cohesionador capaz de fomentar el espíritu emprendedor de los jóvenes y niños de la comunidad de tejedores de sombreros; además, permite que los estudiantes universitarios, que participan como voluntarios en el proyecto, se ejerciten como gestores o animadores de la cultura y desarrollen su espíritu solidario.

Palabras-claves: Gestión Cultural. Voluntariado. Animación sociocultural.

\section{EXPERIÊNCIAS SOCIOCULTURAIS E DE VOLUNTARIADO IMPULSIONADOS PELO PROGRAMA DE GESTÃO CULTURAL ACADÊMICO NA UNIVERSIDADE DE PIURA- PERU}

\section{RESUMO}

As experiências descritas estão centradas, especialmente, no Projeto "Alma Tallán", surgido em 2013. No projeto, a animação sociocultural é interpretada como uma ferramenta para incentivar a participação da comunidade na salvaguarda do patrimônio local. A participação da população nas atividades culturais e nas propostas educacionais consolida o patrimônio como recurso para a coesão social capaz de promover o espírito empreendedor em jovens e crianças em uma comunidade de tecelões de chapéus. Da mesma forma, permite que os estudantes universitários, voluntários no projeto, se exercitem como gestores ou animadores de cultura, desenvolvendo seu espírito de solidariedade.

Palavras-chave: Gestão cultural. Voluntariado. Animação sociocultural.

\section{SOCIOCULTURAL ANIMATION AND VOLUNTEERING EXPERIENCES BOOSTED BY THE ACADEMIC PROGRAM OF CULTURAL MANAGEMENT AT THE UNIVERSITY OF PIURA, PERU.}

\section{ABSTRACT}

The described experiences focus especially in "Alma Tallán" Project (2013 -) in which is applied sociocultural animation as a tool to encourage community participation in the defense of local heritage. The participation of locals in the proposed educational and cultural activities consolidates heritage as a cohesive resource able to encourage the entrepreneurial spirit of youth and children from the community of hat weavers. It also gives to university students the odds of training as cultural managers or leaders and the opportunity to develop a solidary spirit.

Keywords: Cultural Management. Volunteering. Sociocultural animation.

Submetido em: Ago. 2016 Aprovado em: Dez. 2016 